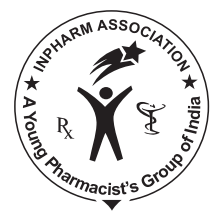

\title{
Medicines in Pharmacy Students' Residence and Self-medication Practices
}

\author{
Auta A, Banwat SB, Sariem CN, Shalkur D, Nasara B, Atuluku MO \\ Department of Clinical Pharmacy, University of Jos, Jos, Nigeria
}

Address for correspondence: Mr. Asa Auta; E-mail: asaauta@yahoo.com

\begin{abstract}
This study was aimed at identifying the types of medicines in pharmacy students' residence and to determine if a relationship exists between keeping medicines in students' accommodation and self-medication practices. A cross-sectional survey of a random sample of 240 undergraduate pharmacy students of the University of Jos, Jos, Nigeria, was carried out. Participating students were given a self-administered questionnaire, and only 188 students returned their filled questionnaire. The data collected were entered and analyzed using SPSS 16 , and the $\chi^{2}$-test was used to determine associations between the variables. The results revealed that $66.0 \%$ of respondents had medicines in their room. A total of 318 medicines items (2.56 items per student's room) of which $37.1 \%$ were leftover medicines were present in respondents' rooms. Analgesics (34.3\%) and antibiotics (25.2\%) were the common classes of medicines present in respondents' rooms. Respondents reported getting these medicines on prescription (25.8\%) and self-medication (56.5\%) or both (17.7\%). Self-medication practice was common among respondents (53.2\%); however, no significant relationship $(P>0.05)$ existed between having medicine in students' room and self-medication practices. Common reasons given by respondents for having medicines in their rooms were that they were leftover medicines and that they were keeping them for emergency use or for use in an event of a similar illness. Most respondents (72.2\%) reported disposing of their unused medicines in a trash can/dust bin. This study demonstrated that the prevalence of medicine storage in students' room and self-medication practice is high. Analgesics and antibiotics were the most common types of medicines present in students' residence.
\end{abstract}

Key words: Leftover medicines, self-medication, students' residence

\section{INTRODUCTION}

Medicines availability and distributions have improved over the years in many developing countries, especially with the

\begin{tabular}{|l|l|}
\hline \multicolumn{2}{|c|}{ Access this article online } \\
\hline Quick Response Code: & \multirow{2}{*}{ Website: } \\
\hline & www.jyoungpharm.in \\
& \\
\hline & DOI: \\
\hline
\end{tabular}

introduction of essential drug programmes. However, the availability of information about rational handling and the use of these medicines is inadequate in many developing countries. ${ }^{[1]}$

Medicines in households lead to medicine wastage which has an economic impact on the health care system. Worldwide, unused (leftover) medicines cost billions of dollars. An estimated cost of unused medicines have been shown to be between NZD $\$ 9$ and 11 billion per annum in New Zealand; ${ }^{[2]}$ about $£ 38$ billion annually in United Kingdom; ${ }^{[3]}$ about AU\$ 1308 per patient annually 
in Australia and about $\$ 150$ million in Saudi Arabia and other Gulf countries. ${ }^{[4]}$

Some reasons identified as causes of unused medicines are over prescribing, a change in the treatment plan, patients no longer in the need of their medicines, adverse drug event, medicines reaching expiry dates, and non-adherence to therapy. ${ }^{[5,6]}$ Studies in the UK showed that about 15 million people do not finish their prescribed medicines and about $30-70 \%$ of patients do not take their medicines as prescribed. ${ }^{[3]}$ These reasons are not exceptions for Africa.

In Nigeria, medicine financing is mainly out-of-pocket, with a few individuals benefiting from the national health insurance scheme. Studies have shown that $23 \%$ of weekly household expenditures in Nigeria are on one episode of illness and consumers pay up to 64 times the international reference price for medicines to obtain medications from facilities. ${ }^{[7]}$ Hence the economic loss due to unused medicines lies on individuals.

Self-medication practices among students have been shown to be common. Awad and Eltayeb studied self-medication practices with antibiotics and antimalarials among Sudanese undergraduate students and concluded that the prevalence of self-medication among students was high. ${ }^{[8]}$ McCabe et al. demonstrated that the non-medical use of prescription drugs is a major problem among secondary school students. ${ }^{[9]}$ Abey and Amelo assessed self-medication practices among medical and para-medical students and concluded that drug authorities and health professionals need to educate students about the pros and cons of self-medication. ${ }^{[10]}$ Verma et al. demonstrated that the prevalence of self-medication among professional students in North India is high. ${ }^{[1]}$ Self-medication was found to be very prevalent (94\%) among university students in Hong Kong. ${ }^{[12]}$ In Nigeria, the antibiotics self-medication pattern among undergraduate students was studied, and the study showed that $56.9 \%$ of respondents reported self-medicating with antibiotics. ${ }^{[13]}$

This study was aimed at identifying the types of medicines found in pharmacy students' residence and to determine if a relationship exists between keeping medicines in students' accommodation and self-medication practices.

\section{MATERIALS AND METHODS}

The study was conducted at the Faculty of Pharmaceutical Sciences, University of Jos, Jos, Nigeria. The faculty has about 450 pharmacy students studying in the four professional years of the pharmacy programme.
A total of 240 students were chosen randomly with at least 50 from each professional level/year to participate in the study. A pre-tested, self-administered questionnaire was distributed among participants after explaining the purpose of the study and obtaining oral informed consent.

The questionnaire used for this study consisted of 20 questions, and it was divided into four domains. The first domain consisted of the demographic details of the respondent; the second domain consisted of questions related to the medicines present in the respondent room; the third domain consisted of questions related to the self-medication practice by respondent; while the fourth domain consisted of questions related to disposal practices. Respondents were asked to take their questionnaires to their residence to enable them record the names of medicines in their residence. Medicines present in students' room were classified according to their pharmacological groups.

Data collected were entered into the statistical package for social sciences (SPSS) for windows version 16.0 (SPSS Inc, Chicago IL) to generate descriptive statistics. Data were analyzed using $\chi^{2}$-test to establish associations between variables.

\section{RESULTS}

A total of 188 of the 240 (representing 78.3\%) questionnaire administered were completely filled and returned by respondents. The respondents consisted of $55.3 \%$ males and $44.7 \%$ females with the majority of the respondents between the ages of 21 and 25 years [Table 1].

The results revealed that 124 respondents had medicines in their room representing $66 \%$ of respondents. Respondents

Table 1: Demographic characteristics of respondents

\begin{tabular}{lc}
\hline Variables & Frequency (\%) \\
\hline Gender & \\
Male & $104(55.3)$ \\
Female & $84(44.7)$ \\
Age in years & \\
$15-20$ & $32(17.0)$ \\
$21-25$ & $69(63.9)$ \\
$26-30$ & $45(23.9)$ \\
$31-35$ & $3(1.6)$ \\
Accommodation & \\
University accommodation & $77(41.0)$ \\
Private accommodation & $111(59)$ \\
Professional year & \\
First & $52(27.7)$ \\
Second & $48(25.5)$ \\
Third & $38(20.2)$ \\
Fourth & $50(26.6)$ \\
\hline
\end{tabular}


reported getting the medicines in their room on prescription (25.8\%), self-medication $(56.5 \%)$, and $17.7 \%$ of respondents reported getting their medicines on both prescription and self-medication. The self-medication practice was common among respondents (53.2\%); however, no significant relationship $\left(\chi^{2}\right.$-value obtained was 2.718 , at 1 degree of freedom with a resultant $P$ value of 0.099 ) exists between having medicine in the room and self-medication practice when $\chi^{2}$-test was applied to the data collected. In addition, there were no associations $(P>0.05)$ between these variables and any of the demographic variable studied [Table 2]. About $26.9 \%$ of medicines used for self-medication were obtained from the medicines available in respondents' rooms [Figure 1]. Only $44.1 \%$ of the medicines items present in respondents' rooms were in their original pack, and about $60.0 \%$ of the respondents reported checking the expiry date of their medicines prior to use.

Respondents reported having about 318 medicines items (representing 2.56 items per student's room) in all, with the tablets $(62.3 \%)$ being the most common dosage form [Table 3] and analgesics and antibiotics being the common classes of medicines present in their rooms [Table 4]. The common sources of these medicines were community pharmacy and the patent medicine stores [Figure 2].

Common reasons given by respondents for having the medicines in their rooms were that the medicines were leftover medicines and that they were keeping the medicine for emergency use or in an event of a similar illness [Table 5].

Table 2: Proportion of respondents that had medicines in their room and those that self-medicate

\begin{tabular}{|c|c|c|c|c|}
\hline Variables & $\begin{array}{l}\text { No. having } \\
\text { medicine } \\
\text { in their } \\
\text { room }(\%)\end{array}$ & $P$ value & $\begin{array}{l}\text { No. that } \\
\text { self- } \\
\text { medicated }\end{array}$ & Pvalue \\
\hline Gender & & 0.1548 & & 0.3380 \\
\hline Male & $64(61.5)$ & & $53(51.0)$ & \\
\hline Female & $60(71.4)$ & & $47(56.0)$ & \\
\hline Age in years & & 0.3424 & & 0.2659 \\
\hline $15-20$ & $25(78.1)$ & & $23(71.9)$ & \\
\hline $21-25$ & $69(63.9)$ & & $53(76.8)$ & \\
\hline $26-30$ & $28(62.2)$ & & $21(46.7)$ & \\
\hline $31-35$ & $2(66.7)$ & & $3(100)$ & \\
\hline Accommodation & & 0.8049 & & 0.4666 \\
\hline University accommodation & $50(64.9)$ & & $42(54.5)$ & \\
\hline Private accommodation & $74(66.7)$ & & $58(52.3)$ & \\
\hline Professional year & & 0.0617 & & 0.0535 \\
\hline First & $37(71.2)$ & & $31(59.6)$ & \\
\hline Second & $34(70.8)$ & & $30(62.5)$ & \\
\hline Third & $18(47.3)$ & & $11(28.9)$ & \\
\hline Fourth & $35(70.0)$ & & $28(56.0)$ & \\
\hline Overall & $124(66.0)$ & & $100(53.2)$ & \\
\hline
\end{tabular}

Journal of Young Pharmacists Vol 4 / No 2
Leftover medicines reported by respondents consisted of about 118 medicine items representing $37.1 \%$ of the total medicine items in students' rooms. Common classes of medicines reported as leftover medicines were analgesics (36.4\%), antibiotics (33.1\%), and antihistamines (11.9\%) [Figure 3]. Most respondents (72.2\%) reported disposing of their unused medicines in a trash can/dust bin [Table 6].

\section{DISCUSSION}

The study revealed that a high proportion of students $(66 \%)$ had medicines in their rooms with an average of 2.56 medicines per student room. This is not surprising because in developing countries, self-medication is high

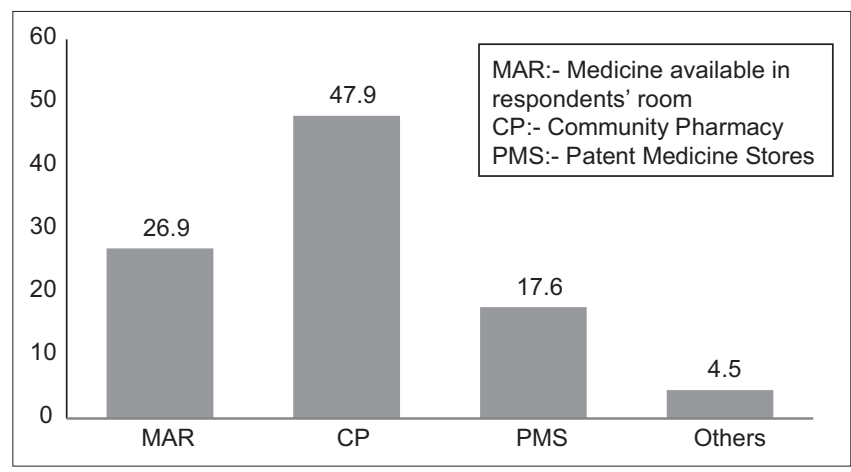

Figure 1: Sources of medicine used for self-medication by respondents

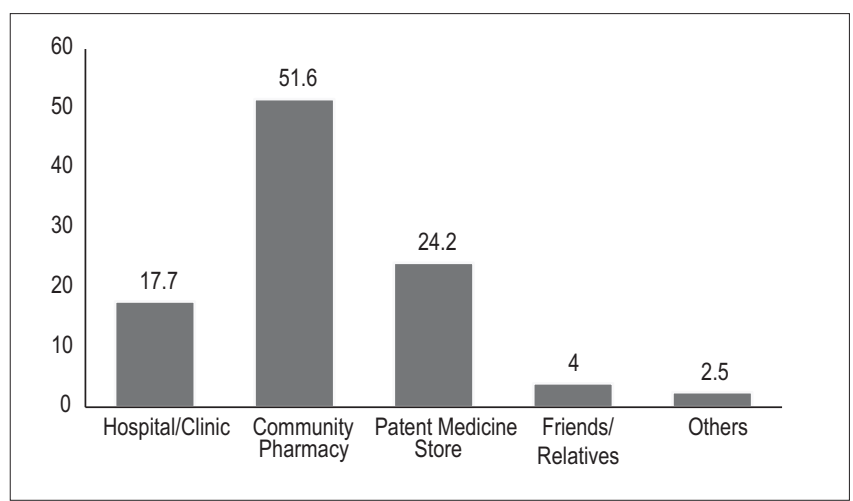

Figure 2: Sources of the medicines present in respondents' room

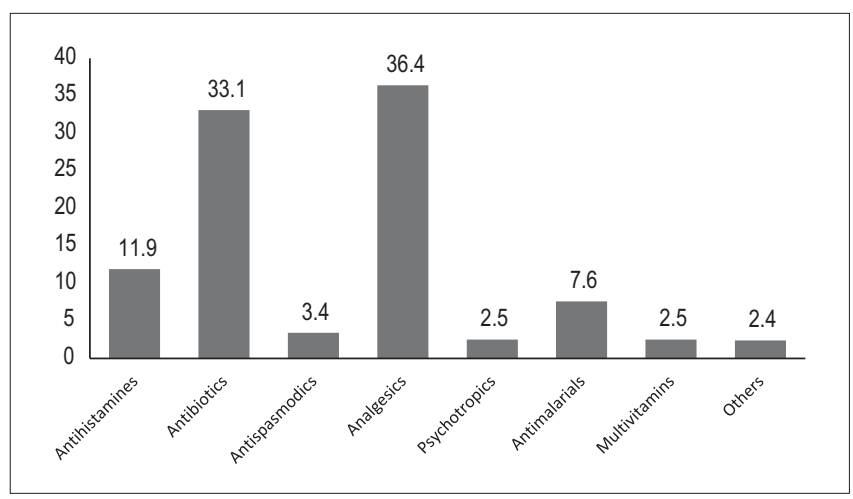

Figure 3: Classes of leftover medicines present in respondents' room 
Table 3: Number of medicine items according to dosage forms in respondents' rooms

\begin{tabular}{lc}
\hline Dosage form & Frequency (\%) \\
\hline Tablets & $198(62.3)$ \\
Capsules & $52(16.4)$ \\
Injectables & $3(0.9)$ \\
Syrups/suspensions & $20(6.3)$ \\
Lotions/creams & $37(11.6)$ \\
Others & $8(2.5)$ \\
\hline
\end{tabular}

Table 4: Classes of medicines found in respondents' rooms

\begin{tabular}{lc}
\hline Class & Frequency (\%) \\
\hline Antihistamines & $38(11.9)$ \\
Antibiotics & $80(25.2)$ \\
Antispamodics & $11(3.5)$ \\
Analgesics & $109(34.3)$ \\
Psychotropic agents & $8(2.5)$ \\
Antimalarials & $24(7.5)$ \\
Antacids/antiulcer agents & $13(4.0)$ \\
Antidiarrhea & $4(1.3)$ \\
Multivitamins & $20(6.3)$ \\
Others & $11(3.5)$ \\
\hline
\end{tabular}

Table 5: Reasons given by respondents for having medicines in their room

\begin{tabular}{lc}
\hline Reason & Frequency (\%) \\
\hline Emergency/first aid & $38(25.9)$ \\
Regular medicine & $24(16.3)$ \\
Left over medicine & $43(29.3)$ \\
Keeping for similar illness & $38(25.9)$ \\
Other reasons & $4(2.7)$ \\
\hline
\end{tabular}

Table 6: Medicine disposal practices among respondents

\begin{tabular}{lc}
\hline Medicine disposal site & Frequency (\%) \\
\hline Trash can/dust bin & $96(72.7)$ \\
Sink & $6(4.5)$ \\
Toilet & $17(12.9)$ \\
Burn medicine & $13(9.9)$ \\
\hline
\end{tabular}

and medicines are kept for re-use in the event of a similar illness or to give it to someone else who might have a similar problem with them. ${ }^{[14]}$ This study also confirm these findings as self-medication among respondents were high $(53.2 \%)$ and respondents reported keeping medicines at home for re-use in case of similar illness and having leftover medicines as reasons for having medicines in their room. Leftover medicines are due to non-adherence to therapy, change in the treatment plan, or over-supply of medicines and this can result in medicine wastage. ${ }^{[6]}$ Therefore, the high percentage $(37.1 \%)$ of leftover medicines found in this study calls for interventions to reduce medication wastage.

The common classes of medicines found in students' rooms were analgesics and antibiotics. In Nigeria, analgesics are the most commonly procured medicines and they are usually obtained over the counter. As a result, self-medication with this class of medicines is high. They are usually the first-line medicines used by community members in an event of an illness. This is because most illnesses present with pain and fever and these medicines are mostly used for symptomatic relief. Most households therefore keep analgesics at home for use in an event of any health problem. However, their use can lead to adverse effects. For example, they can contribute to increased risk of liver and kidney damage when taken in high doses. ${ }^{[15]}$

The high amount of antibiotics found in students' rooms is an indication of inappropriate use of antibiotics. These antibiotics could be as a result of noncompliance to prescribed antibiotics, over prescription of antibiotics or antibiotics obtained as a result of self-medication. This is evident in the high amount of antibiotics reported as leftover medicines by respondents [Figure 3]. Inappropriate use and resistance to antibiotics have been reported in developing countries, and this is a major challenge in the treatment of infectious diseases in developing countries where antibiotics are usually obtained without a prescription. ${ }^{[16,17]}$

About $66 \%$ of the medicine items present in the students' rooms were not in their original packages. When medicines are stored outside their original packages, individuals may not be able to benefit from the vital medicine information contained in either the medicine leaflets/inserts or in some cases information written on medicine packages and this can result in inappropriate handling and use of medicines. In addition, it can also lead to the administration of expired medicines as some medicines have their expiry date written on their packaging.

In Nigeria, basic education on appropriate disposal of unused medicines is lacking. Unused/expired medications are not returned to pharmacies for appropriate disposal as obtainable in other developed countries. None of the respondents indicated returning unused medications to pharmacies. The majority of respondents reported that they dispose unused and expired medications in dustbin/trash cans. Disposing medicines in refuse dumps can have adverse effects on pets and humans, especially children. ${ }^{[18]}$ The accumulations of pharmaceutical compounds in the environment have been reported. Pharmaceuticals have been found in soil, ground water, surface water, and drinking water. ${ }^{[1,20]}$ However, no such studies have been done in Nigeria, but it is likely that these compounds are accumulating in the environment, since they are mostly disposed in refuse dumps. Hence there is the need for public education on appropriate disposal of 
medicines. In addition, the government should encourage the reverse distribution network in which community members are encouraged to return unwanted medications to pharmacies which then arrange for approved agents or bodies to collect and destroy them. ${ }^{[21]}$

\section{Study limitation}

This study was based on the self-reported presence of medicines in respondents' residence. It is therefore possible that the medicines were under-reported or some names of unidentified medicines were wrongly reported.

\section{CONCLUSION}

This study demonstrated that the prevalence of medicine storage in students' rooms and self-medication practices is high. No relationship exists between keeping of medicine in the student rooms and self-medication practices. Analgesics and antibiotics were the most common types of medicines present in students' residences. There is therefore need for education on appropriate handling and use of medicines by students.

\section{REFERENCES}

1. Kiyingi KS, Lauwo JA. Drugs in the home: Danger and waste. World Health Forum 1993;14:381-4.

2. Braund R, Gn G, Mathews R. Investigating unused medications in New Zealand. Pharm World Sci 2009;31:664-9.

3. Zargarzadeh AH, Tavakoli N, Hassanzadeh A. A survey on the extent of medication storage and wastage in urban Iranian households. Clin Ther 2006;27:970-8.

4. Hisham SA. An economic assessment of the extent of medication use and wastage among families in Saudi Arabia and Arabian Gulf countries. ClinTher 2003;25:1276-92.

5. James TH, Helms ML, Braund R. Analysis of medicines returned to community pharmacies. Ann Pharmacother 2009;43:1631-5.
6. Ruhoy IS, Daughton CG. Beyond the medicine cabinet: An analysis of where and why medications accumulate. Environ Int 2008;34:1157-69.

7. Federal Ministry of Health. Medicine prices in Nigeria: Prices people pay for medicines. Abuja: Federal Ministry of Health; 2006.

8. Awad AI, Eltayeb IB. Self-medication practices with antibiotics and antimalarials among Sudanese undergraduate university students. Ann Pharmacother 2007;41:1249-55.

9. McCabe SE, Boyd CJ, Young A. Medical and nonmedical use of prescription drugs among secondary school students. J Adolesc Health 2007;40:76-83.

10. AbaySM, Amelo W. Assessment of self medication practices among medical, pharmacy and health sciences students in Gondar University, Ethiopia. J Young Pharm 2010;2:306-10.

11. Verma RK, Mohan L, Pandey M. Evaluation of self medication among professional students in North India: Proper statutory drug control must be implemented. Asian J Pharm Clin Res 2010;3:60-4.

12. Lau GS, Lee KK, Luk CT. Self-medication among university students in Hong Kong. Asia Pac J Public Health 1995;8:153-7.

13. Olayemi OJ, Olayinka BO, Musa AI. Evaluation of antibiotic self-medication pattern amongst undergraduate students of Ahmadu Bello University (Main Campus) Zaria. Res J Applied SciEng Tech 2010;2:35-9.

14. Auta A, Omale S, Shalkur D, Abiodun AH. Unused medicines in Nigerian households: Types and disposal practices. J Pharmacol Pharmacother 2011;2:195-6.

15. Linden KA. Pharmacoepidemiological study of medicine use among finish conscripts. Ann Med MilitarisFenn 2005;2:6-113.

16. Wongpoowarak P, Wanakamanee U, Panpongtham K, Trisdikoon P, Wongpoowarak W, Ngorsuraches S. Unused medications at home: Reasons and cost. Int J Pharm Pract 2004;12:141-8.

17. Awad A, Eltayeb I, Matowe L, Thalib L. Self-medication with antibiotics and antimalarials in the community of Khartoun State, Sudan. J Pharm PharmSci 2005;8:326-31.

18. Ali SE, Ibrahim MI, Palaian S. Medication storage and self-medication behaviour among female students in Malaysia. Pharm Pract 2010;8:226-32.

19. Tong AY, Peake BM, Braund R. Disposal practices for unused medications around the world. Environ Int 2011;37:292-8.

20. Coma A, Modamio P, Lastra CF, Bouvy ML, Marino EL. Returned medicines in community pharmacies of Barcelona, Spain. Pharm World Sci 2008;30:272-7.

21. Abahussain EA, Ball DE, Matowe WC. Practice and opinion towards disposal of unused medication in Kuwait. Med Princ Pract 2006;15:352-7.

How to cite this article: Auta A, Banwat SB, Sariem CN, Shalkur D, Nasara B, Atuluku MO. Medicines in Pharmacy Students' Residence and Self-medication Practices. J Young Pharmacists 2012;4:119-23.

Source of Support: Nil, Conflict of Interest: None declared.

\section{New features on the journal's website}

Optimized content for mobile and hand-held devices

HTML pages have been optimized of mobile and other hand-held devices (such as iPad, Kindle, iPod) for faster browsing speed.

Click on [Mobile Full text] from Table of Contents page.

This is simple HTML version for faster download on mobiles (if viewed on desktop, it will be automatically redirected to full HTML version)

\section{E-Pub for hand-held devices}

EPUB is an open e-book standard recommended by The International Digital Publishing Forum which is designed for reflowable content i.e. the text display can be optimized for a particular display device.

Click on [EPub] from Table of Contents page.

There are various e-Pub readers such as for Windows: Digital Editions, OS X: Calibre/Bookworm, iPhone/iPod Touch/iPad: Stanza, and Linux: Calibre/Bookworm.

\section{E-Book for desktop}

One can also see the entire issue as printed here in a 'flip book' version on desktops.

Links are available from Current Issue as well as Archives pages.

Click on View as eBook 